\title{
Protective Effect of Alpina nigra Leaves Extract in Mouse Liver Injury Induced by Carbon Tetrachloride
}

\author{
A. M. T. Islam¹, M. A. U. Chowdhury', M. E. Uddin' ${ }^{1}$, M. R. Islam', F. Sharmen ${ }^{2}$, M. S. \\ Parvin $^{3}$, M. E. Islam ${ }^{3 *}$ \\ ${ }^{1}$ Department of Pharmacy, International Islamic University Chittagong, Bangladesh \\ ${ }^{2}$ Genetic Engineering and Biotechnology Department, Chittagong University, Bangladesh \\ ${ }^{3}$ Department of Pharmacy, University of Rajshahi, Rajshahi-6205, Bangladesh
}

Received 26 February 2016, accepted in final revised form 12 April 2016

\begin{abstract}
The present study was aimed to evaluate the hepatoprotective activity of methanol extract against carbon tetrachloride $\left(\mathrm{CCl}_{4}\right)$ induced hepatic damage in rats. $\mathrm{CCl}_{4}$ caused liver damage in rats manifested by significant rise in serum enzyme levels. To examine the effect of the extract male albino rats were used and extract was administered orally at a dose of $300 \mathrm{mg} / \mathrm{kg}$ once daily. The results obtained showed that there were reductions in the activities of serum SGOT, SGPT, ALP, total protein, total bilirubin from $97.67 \pm 1.78,275.67 \pm 2.86,934 \pm 1.41,1.13 \pm 0.227$ and $7.50 \pm 0.707$ in animals treated with toxic doses of $\mathrm{CCl}_{4}$ to $78.33 \pm 1.08,53 \pm 1.41,870 \pm 0.707,0.67 \pm 0.04$ and $6.47 \pm 0.356$ in animal treated with extract before $\mathrm{CCl}_{4}$ intoxication. The extract could also repair the abnormal lipid profile. From these results, it is concluded that methanol extract of Alpina nigra leaves has hepatoprotective activity in $\mathrm{CCl}_{4}$-induced hepatic damage in rats.
\end{abstract}

Keywords: Methanol extract; Hepatotoxicity; $\mathrm{CCl}_{4}$; Leaves.

(C) 2016 JSR Publications. ISSN: 2070-0237 (Print); 2070-0245 (Online). All rights reserved. doi: http://dx.doi.org/10.3329/jsr.v8i3.26842 J. Sci. Res. 8 (3), 381-386 (2016)

\section{Introduction}

Many of the developing countries practice traditional medicine as its main source of healthcare, which is usually of plant origin [1,2]. Today, nearly $88 \%$ of the global populations switch to plant derived medicines as their first line of defense for maintaining health and combating diseases [3]. In future, the discovery of novel therapeutic agents will be only dependent on plant origin [4].

\footnotetext{
Corresponding author: ekram@ru.ac.bd
} 
Liver, the largest organ in vertebrate body, is the major site of intense metabolic activities. Liver injury caused by toxic chemicals and certain drugs has been recognized as a toxicological problem. Herbal drugs are playing an important role in health care program Worldwide, and there is a resurgence of interest in herbal medicines for treatment of various ailments including hepatopathy. India, the abode of Ayurvedic system of medicine, assigns much importance to the pharmacological aspects of many plants. Hepatoprotective effect of some plants like Spirulina maxima [5], Eclipta alba [6], Boehmeria nivea [7], Cichorium intybus [8], Picrorhiza kurroa [9], Maydis stigma (10), Gmelina arborea Roxb.(11) and Manilkara zapota [12] etc. has been well established.

Alpinia nigra belongs to the family Zingiberaceae, is an aromatic plant which is distributed primarily in Yunnan and Hainan Province of China, Thailand and other Southeast Asian countries [13]. It is not only an edible vegetable, but also used in folk remedies to treat dyspepsia, gastric disease and insect bites [14]. In its phytochemical investigation two flavone glycosides, astragalin (1) and kaempferol3-O-glucuronide (2), along with three dihydroxypropyl esters from the seed clusters of this plant were isolated [15]. $\beta$-Pinene and $\alpha$-pinene were found to be major constituents of the volatile oil of the Alpinia nigra fruits [16]. It has been reported that astragalin and kaempferol-3-O-glucuronide isolated from Vahlia capensis and kaempferol-3-O-glucuronide from Rubus ulmifolius showed antibacterial activity [17]. Antioxidant [6-8], antiprotozoal [9], hepatoprotective [18] and glycation inhibitory effects [19] were also observed with these two bioactive compounds. Despite reports on the use of folk medicine together with reports on medicinal potentials of this plant, information on the hepatoprotective activity is unavailable to the best of our knowledge. So, the current investigation is an attempt to study the hepatoprotective of the methanolic extract of Alpinia nigra leaves.

\section{Experimental}

\subsection{Preparation of extracts}

The collected plant was identified by Botany Department of Chittagong University, Bangladesh. It was washed thoroughly with water, chopped, dried in shade for a week at $35-40^{\circ} \mathrm{C}$ and pulverized in electric grinder. The powder obtained was successively extracted in methanol $\left(55-60^{\circ} \mathrm{C}\right)$. The extracts were made to dry by using rotary evaporator under reduced pressure.

\subsection{Animals}

Male albino rats weighing 100-120 g were obtained from the Animal house of the International Centre for Diarrhoeal Disease and Research, Bangladesh (ICDDR, B). The animals were housed under standard laboratory conditions (relative humidity 55-65\%, room temperature $23.0 \pm 2.0^{\circ} \mathrm{C}$ and $12 \mathrm{~h}$ light: dark cycle). They were fed with standard 
diet and water ad libitum. The set of rules followed for animal experiment were approved by the institutional animal ethics committee, Department of Pharmacy, International Islamic University Chittagong, Bangladesh according to governmental guidelines [20].

\section{3. $\mathrm{CCl}_{4}$ induced hepatotoxicity}

The hepatoprotective activity of the extract was determined using carbon tetrachloride $\mathrm{CCl}_{4}$ induced hepatotoxic in rat model. After seven days of acclimatization, the rats were divided into four groups each comprising of three rats and treatment was done for 7 days. Group I served as normal control and received only saline ( $1 \mathrm{ml} / \mathrm{kg}$, i.p.) for seven days. Group II-IV received $\mathrm{CCl}_{4}\left(\mathrm{CCl}_{4}\right.$ : liquid paraffin 1:2:1 ml/kg i.p.) once in every $72 \mathrm{~h}$ where Group-II served as $\mathrm{CCl}_{4}$ control group. Test group animals (Group III) received extract (300 mg/kg daily, p.o.) and Group IV received standard drug silymarin ( $25 \mathrm{mg} / \mathrm{kg} /$ day, p.o.). After $24 \mathrm{~h}$ of the last dose, blood was withdrawn from retro-orbital plexus under sodium phenobarbital anesthesia and the rats were dissected to isolate the liver. Before collecting the blood, the syringe was rinsed with heparin to prevent hemolysis. The blood samples were then centrifuged at $2500 \mathrm{rpm}$ for $10 \mathrm{~min}$ to separate serum and was used for the assay of the biochemical markers of liver damage viz. serum glutamate pyruvate transaminase (SGPT), serum glutamic oxaloacetic transaminase (SGOT) [21], alkaline phosphatase (ALP) [22], bilirubin [23], total protein [24] and lipid profile (cholesterol,_LDL, HDL,_TG) by using commercially available kits.

\subsection{Statistical analysis}

All the results are shown as average \pm S.E.M. Data was statistically evaluated by oneway analysis of variance (ANOVA) followed by post hoc Dunnett's test using SPSS software. $P<0.01$ and $P<0.001$ were considered as statistically significant.

\section{Results and Discussion}

Biochemical parameters (SGOT, SGPT, ALP, total protein, total bilirubin) and lipid profile are shown in Table 1. The level of SGPT, SGOT, ALP, total bilirubin and total protein were restored towards the normal value in extract and silymarin treated $\mathrm{CCl}_{4}$ intoxicated rats which indicate the index of their hepatoprotective effects. There was a significant increase in lipid profile, viz. cholesterol, LDL, triglycerides whereas HDL level was decreased in $\mathrm{CCl}_{4}$ control group compared to that of normal control group of rat. However, treatment with plant extract and silymarin repaired the abnormal lipid profile towards optimum level which was also indicator of protective effect of plant extract against hepatic damage. 
Table 1. Effect of methanol extract of Alpinia nigra leaves on biochemical parameters on $\mathrm{CCl}_{4}$ induced liver damage of rats.

\begin{tabular}{llcllll}
\hline Groups & Treatment & SGPT (U/L) & SGOT (U/L) & ALP (U/L) & $\begin{array}{l}\text { Bilirubin } \\
(\mathrm{mg} / \mathrm{dL})\end{array}$ & $\begin{array}{l}\text { Total protein } \\
(\mathrm{mg} / \mathrm{dL})\end{array}$ \\
\hline Group I & Control & $21.667 \pm 1.08^{* *}$ & $24.33 \pm 4.71^{* *}$ & $18.67 \pm 1.08^{* *}$ & $0.50 \pm 0.07$ & $5.80 \pm 0.286$ \\
Group II & $\mathrm{CCl}_{4}$ & $97.67 \pm 1.78^{* *}$ & $275.67 \pm 2.86^{* *}$ & $934 \pm 1.41^{* *}$ & $1.13 \pm 0.227$ & $7.50 \pm 0.707$ \\
Group III & Extract $+\mathrm{CCl}_{4}$ & $78.33 \pm 1.08^{* *}$ & $53 \pm 1.41^{*}$ & $870 \pm 0.707 * *$ & $0.67 \pm 0.04$ & $6.47 \pm 0.356$ \\
Group IV & Silymarin $+\mathrm{CCl}_{4}$ & $30 \pm 1.41^{* *}$ & $148 \pm 5.34 * *$ & $516.67 \pm 2.48^{* *}$ & $0.90 \pm 0.07$ & $6.30 \pm 0.141$ \\
\hline
\end{tabular}

Values are Mean \pm SEM and each group contained three rats. Drug treatment was done for 7 days.

$* P<0.01, * * P<0.001=$ Experimental groups compared with control group; where the significance was performed by One way ANOVA followed by post hoc Dunnett's test.

Table 2. Effect of methanol extract of Alpinia nigra leaves on lipid profile on $\mathrm{CCl}_{4}$ induced liver damage of rats.

\begin{tabular}{|c|c|c|c|c|c|}
\hline Groups & Treatment & $\begin{array}{c}\text { Cholesterol } \\
(\mathrm{mg} / \mathrm{dL})\end{array}$ & HDL (mg/dL) & LDL (mg/dL) & TG (mg/dL) \\
\hline Group I & Control & $106.33 \pm 1.47 * *$ & $24.67 \pm 1.78^{* *}$ & $65.37 \pm 1.46^{* *}$ & $84.67 \pm 1.79 * *$ \\
\hline Group II & $\mathrm{CCl}_{4}$ & $144 \pm 1.87 * *$ & $114 \pm 2.83^{* *}$ & $55 \pm 1.41 * *$ & $212.33 \pm 1.78^{* *}$ \\
\hline Group III & Extract $+\mathrm{CCl}_{4}$ & $132.33 \pm 1.47 * *$ & $37.33 \pm 1.08 *$ & $38.13 \pm 1.28 * *$ & $184 \pm 1.08 * *$ \\
\hline Group IV & Silymarin $+\mathrm{CCl}_{4}$ & $118 \pm 1.41 * *$ & $70 \pm 1.41 * *$ & $26.43 \pm 0.521 * *$ & $106.33 \pm 3.89^{* *}$ \\
\hline
\end{tabular}

Values are Mean \pm SEM and each group contained three rats. Drug treatment was done for 7 days. $* P<0.01,{ }^{*} P<0.001=$ Experimental groups compared with control group; where the significance was performed by One way ANOVA followed by post hoc Dunnett's test.

In the present study, the methanolic extract of Alpinia nigra leaves was evaluated for the hepatoprotective activity by $\mathrm{CCl}_{4}$ induced hepatotoxicity in rat model. $\mathrm{CCl}_{4}$ has been used extensively to investigate hepatoprotective activity on various experimental animals which produces an experimentally damage that histologically resembles viral hepatitis $[25,26]$. Silymarin, which is an active constituent of the fruit of the milk thistle (Silybum marianum, Compositae) used as standard drug and hepatoprotective activity of the extract was compared. $\mathrm{CCl}_{4}$ is biotransformed by cytochrome $\mathrm{P} 450$ in the liver endoplasmic reticulum to the highly reactive trichloromethyl free radical. This free radical in turn reacts with oxygen to form trichloromethylperoxy radical, which may attack lipids on the membrane of endoplasmic reticulum more readily than the trichloromethyl free radical [27].

Trichloromethyl peroxy radical leads to elicit lipid peroxidation, the distribution of $\mathrm{Ca}^{+}$homeostasis, elevation of hepatic enzymes and finally results in cell death [28]. This affects the functional integrity of the membranes of plasma, mitochondria and endoplasmic reticulum, resulting in the loss of calcium sequestration and homeostasis and consequently leading to liver damage. This hepatic injury is responsible for the leakage of cellular enzymes into the blood. The lowering of enzyme level is a definite indication of hepatoprotective action of the drug. The result in this investigation suggests that feeding rats with Alpinia nigra leaves extract resulted in normalization of elevated serum marker enzymes (SGPT, SGOT, ALP) and bilirubin in the treatment group relative to the control groups due to protective and repair actions of the extract against hepatic injury by $\mathrm{CCl}_{4}$. Extract also increased protein synthesis in the test control group probably through increased methylation of RNA that was inhibited by 
$\mathrm{CCl}_{4}$. The serum lipid profile such as total cholesterol, triglycerides, LDL were elevated and HDL was decreased, this indicated deterioration in hepatic function by $\mathrm{CCl}_{4}$ administration. The characteristic changes were observed in the concentrations of plasma lipids profile in rats treated with methanol extract. It is known that there is a beneficial relationship between antioxidant and hepatoprotective activity of plants extract [29]. The leaves of Alpina nigra contain some flavonoinds and phenolic constituents which have strong antioxidant activity. The possible mechanism of hepatoprotective activity of Alpinia nigra leaves may be due to its antioxidant activity. Further studies are in progress regarding the isolation and characterization of the active principles responsible for hepatoprotective activity.

\section{Conclusion}

The crude extract of the plant is the composition of diverse phytochemical constituents which may show synergistic, inhibitory as well as toxic effects through different molecular mechanisms. So, isolation and purification of the crude extract and their therapeutic evaluation is uttermost important to get ultimate benefit from the plant. Besides, structural elucidation of the purified compounds may enable us to develop and synthesize new drugs through structural activity relationship. Therefore, further exploration of the crude leaves extract of Alpina nigra through modern phytochemical, pharmacological, pharmacokinetic and clinical approaches is essential to make it therapeutically applicable in the treatment of oxidative liver damage.

\section{References}

1. R. Ahmad, S. P. Srivastava, R. Maurya, S. M. Rajendran, K. R. Arya, and A. K. Srivastava, Ind. J. Sci. Technol. 1, 5 (2008).

2. S. Bent, J. General Intl. Med. 23, 854 (2008). http://dx.doi.org/10.1007/s11606-008-0632-y

3. Kintzios and E. Spiridon, Critical Rev. Plant Sci. 25, (2006).

4. R. R. Majinda, M. Motswaledi, and R. D. Waigh, Planta Med. 63, 268 (1997). http://dx.doi.org/10.1055/s-2006-957671

5. L. Panizzi, C. Caponi, and S. Catalano, J. Ethnopharmacol. 79, 165 (2002). http://dx.doi.org/10.1016/S0378-8741(01)00363-4

6. G. W. Plumb, K. R. Price, and G. Williamson, Redox Rep. 4, 123 (1999). http://dx.doi.org/10.1179/135100099101534800

7. P. Apati and P. J. Houghton, A. Kery, Acta Pharm Hung. 74, 223 (2004).

8. J. T. Han, M. H. Bang, and O. K. Chun, Arch. Pharm. Res. 27, 390 (2004). http://dx.doi.org/10.1007/BF02980079

9. C. Fernando and D. A. Alma, Phytother. Res. 21, 78 (2007). http://dx.doi.org/10.1002/ptr.2031

10. K. Z. Peng, X. Yang, H. L. Zhou, and S. X. Pan. Molecules 20, 22102 (2015). http://dx.doi.org/10.3390/molecules201219835

11. A. P. Attanayake, K. A. P. W. Jayatilaka, C. Pathirana, and L. K. B. Mudduwa. J. Med. Nutri. Neutraceuticals. 4(1), 32 (2015). http://dx.doi.org/10.4103/2278-019X.146159

12. M. R. Islam, M. S. Parvin, M. S. Islam, S. M. R. Hasan, and M. E. Islam, J. Sci. Res. 4(1), $193(2012)$

13. D. L. Wu, Flora of China, (Beijing: Science Press, 1981) 16, pp. 67-106. 
14. A. N. Singab, D. Youssef, and E. Noaman, Arch. Pharm. Res. 28, 791 (2005). http://dx.doi.org/10.1007/BF02977344

15. H. Y. Kim, H. Moon, and H. J. Lee, J. Ethnopharmacol. 93, 227 (2004). http://dx.doi.org/10.1016/i.jep.2004.03.047

16. C. Qiao, Q. Hana, J. Song, Z. Wang, L. Xu, and H. Xua, As. J. Trad. Med. 2, 3 (2007).

17. R. R. Majinda, M. Motswaledi, and R. D. Waigh, Planta Med. 63, 268 (1997). http://dx.doi.org/10.1055/s-2006-957671

18. A. O. Karen, J. D. Andrea, and W. N. Paul, FEBS Lett. 503, 103 (2001). http://dx.doi.org/10.1016/S0014-5793(01)02684-9

19. H. Y. Kim, B. H. Moon, and H. J. Lee, J. Ethnopharmacol. 93, 227 (2004). http://dx.doi.org/10.1016/j.jep.2004.03.047

20. M. Zimmermann. Pain. 16, 109 (1983). http://dx.doi.org/10.1016/0304-3959(83)90201-4

21. S. Reitman and S. Frankel, Am. J. Clin. Path. 33, 97 (1957).

22. W. G. Duncombe, Biochem. J. 88, 7 (1963). http://dx.doi.org/10.1042/bj0880007

23. H. T. Mallay and K. A. Evelyn, J. Biol. Chem. 119, 481 (1937).

24. O. H. Lowry, N. J. Rosebrough, A. L. Farr, and R. J. Randall, J. Biol. Chem. 193, 265 (1951).

25. R. O. Recknagel, E. A. Glende, J. A. Dolak, and R. L. Walter, Pharmacol. Ther. 43, 139 (1989). http://dx.doi.org/10.1016/0163-7258(89)90050-8

26. G. A. Clawson, Path. Immunopath. Res. 8, 104 (1989). http://dx.doi.org/10.1159/000157141

27. P. S. Bhathal, N. R. Rose, and I. R. Mackay, Br. J. Exp. Path. 64, 524 (1983).

28. G. W. L. James, R. W. Pickering, Drug Res. 26, 2197 (1976).

29. M. R. Islam, M. S. Parvin, and M. E. Islam, Drug Discov. Ther. 6 (4), 205-11 (2012). 